\title{
Effect of Al on Bulk Amorphization and Magnetic Properties of FeSnPSiB Alloys
}

\author{
Chih-Yuan Lin ${ }^{1}$, Tsung-Shune Chin ${ }^{1,2, *}$, Chih-Kang Chao ${ }^{1}$, Siao-Xion Zhou ${ }^{3}$, Zhih-Chao Lu$^{3}$, \\ Li Wang ${ }^{3}$, Fei-Fei Chen ${ }^{3}$, Ming-Xiang Pan ${ }^{4}$ and Wei-Hua Wang ${ }^{4}$ \\ ${ }^{1}$ Department of Materials Science and Engineering, National Tsing Hua University, \\ 101, Sec. 2. Kuang-Fu Road, Hsinchu, 300, Taiwan, R.O. China \\ ${ }^{2}$ National United University, Miaoli, 360, Taiwan, R.O. China \\ ${ }^{3}$ State Key Laboratory for Amorphous Metals, Central Iron and Steel Institute, Beijing, P.R. China \\ ${ }^{4}$ Institude of Physics, Chinese Academy of Science, Beijing, 100080, P.R. China
}

Structure and magnetic properties of melt-spun multi-component $\mathrm{Fe}_{78-x} \mathrm{Al}_{x} \mathrm{Sn}_{2} \mathrm{P}_{12} \mathrm{Si}_{4} \mathrm{~B}_{4}(x=0,3,4,5$ at $\%)$ amorphous ribbons and copper-mold-cast rods were investigated. The improvement of thermal stability was recognized with the replacement of $\mathrm{Fe}$ by $3 \sim 5 \mathrm{at} \% \mathrm{Al}$ in these Sn-containing alloys. The super-cooled liquid region $\left(\Delta T_{\mathrm{x}}\right)$, defined by $\left(T_{\mathrm{x}}-T_{\mathrm{g}}\right)$ where $T_{\mathrm{x}}$ is the crystallization temperature and $T_{\mathrm{g}}$ the glass transition temperature, increases from $46.5 \mathrm{~K}$ as $x=3$ to the maximum value $50.2 \mathrm{~K}$ as $x=4$. With increasing Al content, magnetic properties of annealed $\mathrm{Fe}_{78-x} \mathrm{Al}_{x} \mathrm{Sn}_{2} \mathrm{P}_{12} \mathrm{Si}_{4} \mathrm{~B}_{4}(x=3 \sim 5$ at\%) amorphous ribbons are: saturation magnetization decreases from 1.22 to 1.18 $\mathrm{T}$; coercive force decreases from 3.3 to $2.2 \mathrm{~A} / \mathrm{m}$, maximum permeability increases from 137000 to 208000 , Curie temperature lowers from $591.1 \mathrm{~K}$ to $578.3 \mathrm{~K}$; the electrical resistivity increases from 175 to $188 \mu \Omega$-cm; and core loss is about $0.14 \mathrm{~W} / \mathrm{kg}(50 \mathrm{~Hz}, 1.1 \mathrm{~T}$ external magnetic field). Bulk amorphous rods with $1 \mathrm{~mm}$ diameter were successfully demonstrated for the composition $\mathrm{Fe}_{74} \mathrm{Al}_{4} \mathrm{Sn}_{2} \mathrm{P}_{12} \mathrm{Si}_{4} \mathrm{~B}_{4}$ by a copper mold casting method. Due to the combination of good glass forming ability and superior soft magnetic properties, these alloys will find potential applications in industries.

(Received August 25, 2003; Accepted January 6, 2004)

Keywords: bulk amorphous alloys, iron-based alloys, FeSnPSiB, FeAlSnPSiB, thermal properties, soft magnetic properties

\section{Introduction}

Since the first synthesis of Fe-P-C amorphous alloys in 1967 by a rapid solidification technique, ${ }^{1)}$ a large number of Fe-based amorphous alloys have been developed subsequently. These alloys are the series of $\left.(\mathrm{Fe}, \mathrm{Co})-(\mathrm{P}, \mathrm{Si})-\mathrm{B},{ }^{2-4}\right)$ $\left.\left.(\mathrm{Fe}, \mathrm{Co})-(\mathrm{Cr}, \mathrm{Mo}, \mathrm{W})-\mathrm{C},{ }^{5}\right) \quad(\mathrm{Fe}, \mathrm{Co})-(\mathrm{Zr}, \mathrm{Hf}),{ }^{6,7}\right) \quad(\mathrm{Fe}, \mathrm{Co})-(\mathrm{Zr}$, $\mathrm{Hf}, \mathrm{Nb})-\mathrm{B}^{8)}$ and etc. Fe-based amorphous alloys have attracted great attention due to their sound soft magnetic properties for applications such as transformer cores. However, it is well known that the cooling rate for these alloys to achieve amorphous state is around $10^{6} \mathrm{~K} / \mathrm{s}$ due to their poor glass forming ability. With such a high cooling rate, the resultant alloy thickness is limited to below $50 \mu \mathrm{m}$ leading to a shape of sheet, ribbon, wire, powder and thin film. The very thin amorphous ribbons render difficulties in the lamination processes of a transformer, and lower packing factor. In recent years, a large number of bulk glassy alloys had been synthesized in multi-component alloys such as Mg-based, $, 9,10$ ) lanthanide metals-based ${ }^{11,12)}$ and Zr-based ${ }^{13-15)}$ alloys, by using various kinds of solidification method such as water quenching or copper mold casting. These bulk amorphous alloys exhibit a wide super-cooled liquid region $\left(\Delta T_{\mathrm{x}}\right)$ over $60 \mathrm{~K}$, which is defined by the difference between glass transition temperature $\left(T_{\mathrm{g}}\right)$ and crystallization temperature $\left(T_{\mathrm{x}}\right)$. The phenomenon of wide super-cooled liquid region corresponds to a high resistance against crystallization. These bulk amorphous alloys satisfy the following three empirical rules: (1) multi-component containing more than three elements; (2) a large difference in atomic size ratios, more than 12\%; and (3) a large negative heats of mixing. Until 1995, a number of new Fe-based bulk amorphous alloys with

*Corresponding author, E-mail: tschin@nuu.edu.tw wide super-cooled liquid region $\left(\Delta T_{\mathrm{x}}\right)$ above $50 \mathrm{~K}$ were developed according to these three empirical rules for achieving high glass forming ability (GFA). The Fe-based bulk amorphous alloys mainly consist of the following groups of elements $\mathrm{Fe}-(\mathrm{Al}, \mathrm{Ga})-(\mathrm{P}, \mathrm{C}, \mathrm{B}, \mathrm{Si}),{ }^{16-19)} \mathrm{Fe}-(\mathrm{Co}, \mathrm{Ni})-$ $(\mathrm{Zr}, \mathrm{Hf}, \mathrm{Nb})-\mathrm{B},{ }^{20-22)} \quad$ (Fe, Co)-( $\left.\left.\mathrm{Zr}, \mathrm{Hf}\right)-(\mathrm{Nb}, \mathrm{Ta})-(\mathrm{Mo}, \mathrm{W})-\mathrm{B},{ }^{23}\right)$ $\left.(\mathrm{Fe}, \mathrm{Co})-\mathrm{Ln}-\mathrm{B}^{24}\right)(\mathrm{Ln}=$ lanthanide metals $)$ and $(\mathrm{Nd}, \mathrm{Pr})-\mathrm{Fe}-$ $\mathrm{Al}^{25-27)}$ systems. The possibility to cast bulk Fe-based amorphous magnetic alloys widely extends their potential in industrial applicability.

FeSnPSiB amorphous alloys capable of melt-spinning into thick amorphous ribbons up to $150 \mu \mathrm{m}$ were developed earlier in our group. ${ }^{28)}$ These alloys though show good magnetic properties were, however, quite brittle not being able to bend over a radius of curvature less than $3 \mathrm{~mm}$ when $\mathrm{Sn}$ content exceeds 2 at $\%$. This study was one of the researches intended to enhance thermal stability, bulk amorphous forming ability, toughness and magnetic properties, by adding some other elements (such as Al in this case) to partly replace Fe in the FeSnPSiB amorphous alloys.

\section{Experimental Procedures}

Multi-component alloy ingots with nominal compositions $\mathrm{Fe}_{78-x} \mathrm{Al}_{x} \mathrm{Sn}_{2} \mathrm{P}_{12} \mathrm{Si}_{4} \mathrm{~B}_{4}(x=0,3,4,5$ at $\%)$ were prepared by induction melting the mixtures of pre-alloyed Fe-P, Fe-B ingots (both were industrial grade), pure $\mathrm{Si}, \mathrm{Sn}$ and $\mathrm{Al}$ beads of at least $99.8 \%$ under a vacuum $0.01 \mathrm{MPa}$. Ribbons with a cross section of about $0.03 \times 10 \mathrm{~mm}^{2}$ were prepared by a single-roller melt-spinning technique. Bulk alloys in rod form with different diameters were prepared by a copper mold casting method. The structures of ribbons and rods were examined by X-ray diffractometry. The thermal stability was studied by differential scanning calorimetry (DSC) at a 


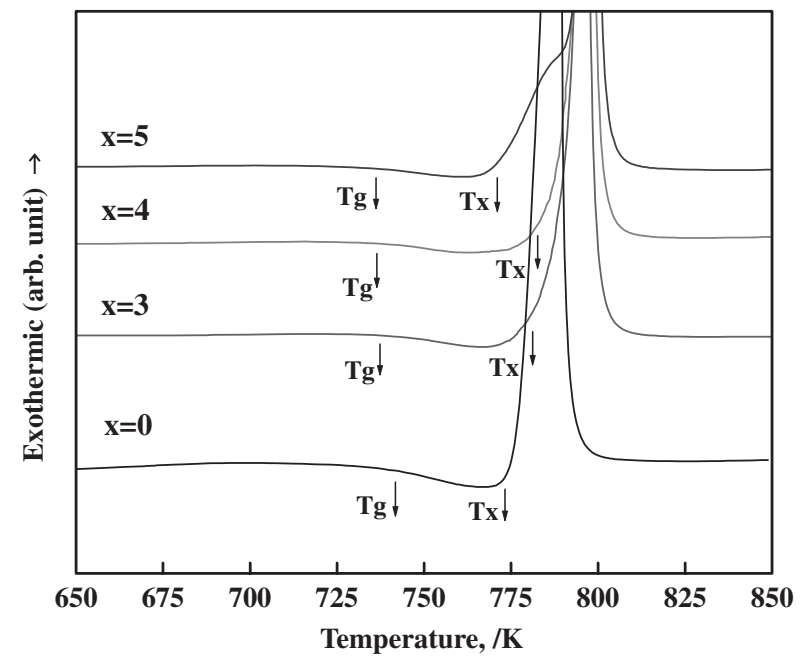

Fig. 1 DSC curves of $\mathrm{Fe}_{78-x} \mathrm{Al}_{x} \mathrm{Sn}_{2} \mathrm{P}_{12} \mathrm{Si}_{4} \mathrm{~B}_{4}(x=0,3,4,5$ at $\%)$ melt-spun amorphous ribbons.

heating rate of $0.67 \mathrm{~K} / \mathrm{s}$. Magnetic properties; including saturation magnetization $\left(I_{\mathrm{S}}\right)$ and coercivity force $\left(H_{\mathrm{c}}\right)$ were measured with a vibrating sample magnetometer (VSM). Permeability was measured with an impedance analyzer. Curie temperature $\left(T_{\mathrm{c}}\right)$ was measured by a magnetic-thermalgravimetric analyzer (M-TGA) at a heating rate of $5 \mathrm{~K} / \mathrm{min}$. Core loss was measured at a frequency of $50 \mathrm{~Hz}$ under different external magnetic fields, typically from 0.5 to $1.1 \mathrm{~T}$ by using an alternating current magnetic measurement. The electrical resistivity was measured by a typical four-point probe method.

\section{Results and Discussion}

\subsection{Structure and thermal properties}

$\mathrm{X}$-ray diffraction profiles showed that all as-melt-spun $\mathrm{Fe}_{78-x} \mathrm{Al}_{x} \mathrm{Sn}_{2} \mathrm{P}_{12} \mathrm{Si}_{4} \mathrm{~B}_{4}(x=0,3,4,5$ at $\%)$ ribbons consist of amorphous phase only. Figure 1 shows DSC curves of meltspun $\mathrm{Fe}_{78-x} \mathrm{Al}_{x} \mathrm{Sn}_{2} \mathrm{P}_{12} \mathrm{Si}_{4} \mathrm{~B}_{4}(x=0,3,4,5$ at $\%)$ amorphous ribbons. It shows that all alloys exhibit a glass transition process followed by a super-cooled liquid region before an exothermic reaction, which indicates the crystallization of the amorphous alloys. The figure also shows that the alloys tend to crystallize through only one stage except the alloy with 5 at\% Al.

Figure 2 shows the changes in $T_{\mathrm{g}}, T_{\mathrm{x}}$ and $\Delta T_{\mathrm{x}}\left(=T_{\mathrm{x}}-T_{\mathrm{g}}\right)$ of the amorphous alloys $\mathrm{Fe}_{78-x} \mathrm{Al}_{x} \mathrm{Sn}_{2} \mathrm{P}_{12} \mathrm{Si}_{4} \mathrm{~B}_{4}(x=0,3,4$, 5 at $\%$ ). The $\Delta T_{\mathrm{x}}$ of the alloys is improved after adding $\mathrm{Al}$, exhibiting a wide super-cooled liquid region, $\Delta T_{\mathrm{x}}$, at least $40.6 \mathrm{~K}$ and reaches the maximum value of $50.2 \mathrm{~K}$ at $4 \mathrm{at} \%$. The crystallized phases of all samples annealed at $823 \mathrm{~K}$ for $3600 \mathrm{~s}$ have been clarified as $\alpha$-Fe, $\mathrm{FeP}, \mathrm{Fe}_{3} \mathrm{P}$ and $\mathrm{FeB}$ compounds, as shown in Fig. 3.

The enlargement of $\Delta T_{\mathrm{x}}$ is due to the reasons that the addition of $\mathrm{Al}$ agrees with the empirical rules for bulk amorphous alloy: (1) one more components of the already multi-component alloy; (2) enlarged atomic size ratio of constituent elements, since the atomic size of $\mathrm{Al}$ is larger than most of other constituent elements (the atomic radius in increasing order is $\mathrm{B}<\mathrm{P}<\mathrm{Si}<\mathrm{Fe}<\mathrm{Al}<\mathrm{Sn}$ ). The addition of

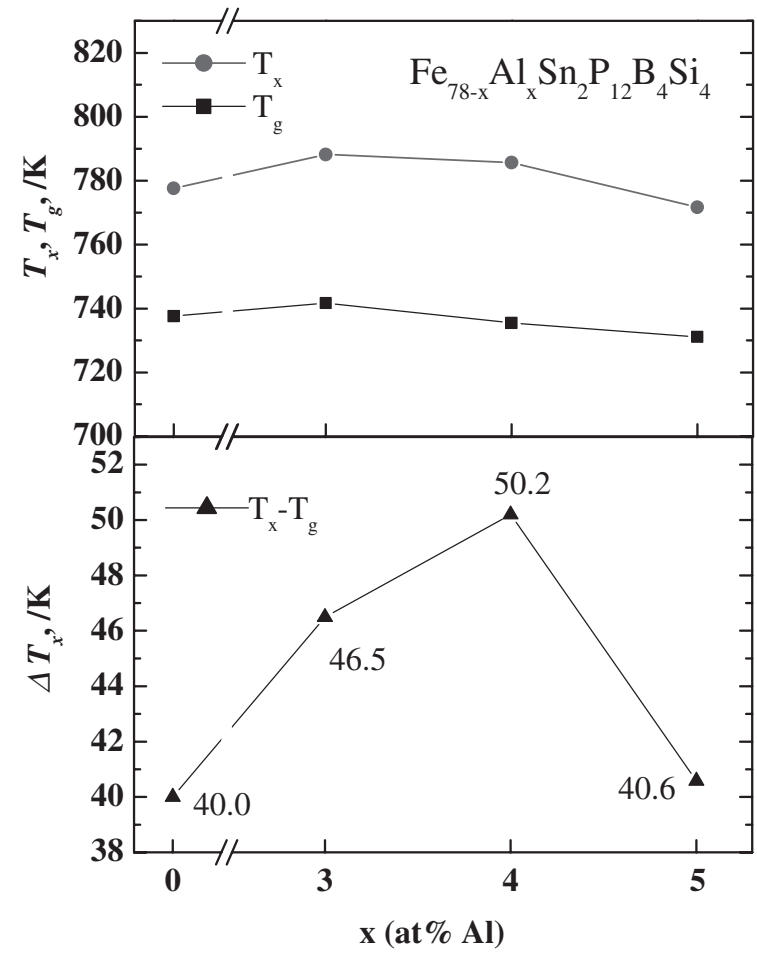

Fig. $2 T_{\mathrm{g}}, T_{\mathrm{x}}$ and $\Delta T_{\mathrm{x}}\left(=T_{\mathrm{x}}-T_{\mathrm{g}}\right)$ as a function of $\mathrm{x}$ for melt-spun $\mathrm{Fe}_{78-x} \mathrm{Al}_{x} \mathrm{Sn}_{2} \mathrm{P}_{12} \mathrm{Si}_{4} \mathrm{~B}_{4}(x=0,3,4,5$ at\%) amorphous ribbons.

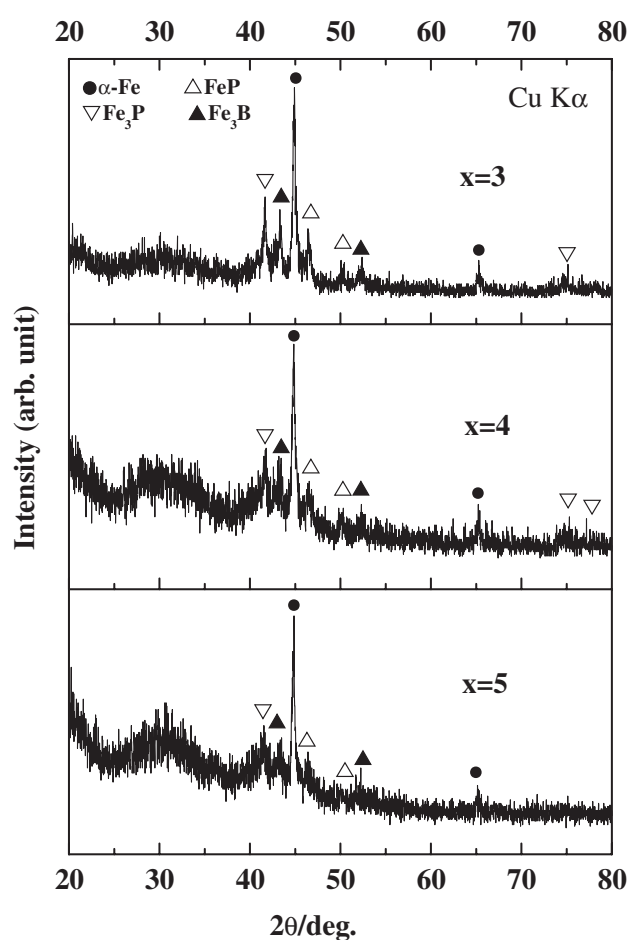

Fig. 3 X-ray diffraction patterns of crystallization-annealed $\mathrm{Fe}_{78-x} \mathrm{Al}_{x} \mathrm{Sn}_{2} \mathrm{P}_{12} \mathrm{Si}_{4} \mathrm{~B}_{4}(x=3,4,5$ at $\%)$ ribbons, annealed at $823 \mathrm{~K}$ for $3600 \mathrm{~s}$.

Al facilitates the degree of random packed structure that retards the atoms to arrange themselves into ordered crystals. And it is also known that $\mathrm{Al}$ has a quite strong chemical bonding nature to other metals (such as $\mathrm{Fe}$ to form $\mathrm{Fe}_{3} \mathrm{Al}$ ) and to metalloids such as $\mathrm{P}$ and $\mathrm{B}$, as is evidenced in the AlP and 
$\mathrm{AlB}_{12}$ compounds with extremely high melting temperature of $2813 \mathrm{~K}$ and $2423 \mathrm{~K},{ }^{29)}$ respectively. The melting temperatures of these Al-metalloid compounds are much higher than those of $\mathrm{FeP}, \mathrm{FeB}$ and $\mathrm{Fe}_{3} \mathrm{~B}$. The dissolution of suitable amount of $\mathrm{Al}$ in the amorphous matrix results in the generation of favorable Al-metalloid pairs. As a consequence the atomic rearrangement required for the precipitation of main crystalline phases will be prevented. However, the mixing heats of $\mathrm{Sn}$ and $\mathrm{Al}$ with other constituent elements in these alloys are positive and small (in case of Sn) and negative and small (in case of Al), respectively. The third empirical rule of the necessary large and negative heat of mixing is considered not being violated since the concentration of $\mathrm{Al}(<5 \mathrm{at} \%)+\mathrm{Sn}(2 \mathrm{at} \%)$ is relatively small compared with the Fe-metalloids ones with truly very large and negative heat of mixing.

The improvement of thermal stability for Fe-P-B-Si alloys was thoroughly investigated earlier by Inoue et al. ${ }^{30)}$ According to DSC curves of our amorphous alloys in Fig. 1, the single-stage crystallization mode also plays an important role for achieving high thermal stability and glass forming ability of the Fe-P-B-Si alloys as explored earlier. ${ }^{31)}$ This phenomenon reveals that all crystalline phases simultaneously crystallize at elevated temperature. This requires a long-range re-distribution of constituent elements and is difficult due to the existence of relatively strong Al-metal, Al-metalloid pairs as mentioned above. As a result the crystallization process will be retarded.

The possibility of forming an amorphous rod sample with a diameter of $1 \mathrm{~mm}$ for $\mathrm{Fe}_{78-x} \mathrm{Al}_{x} \mathrm{Sn}_{2} \mathrm{P}_{12} \mathrm{Si}_{4} \mathrm{~B}_{4}(x=0,3,4$, 5 at\%) alloys has also been examined by a copper mold casting method. As shown in Fig. 4, the degree of crystallization of as-cast samples decreases after adding $\mathrm{Al}$, as evidenced from diminishing X-ray diffraction peaks. The bulk amorphous rod with a diameter $1 \mathrm{~mm}$ was successfully achieved at $\mathrm{Al}$ content $4 \mathrm{at} \%$. We also further examined the possibility of casting the amorphous rod in larger diameters, $1.5 \mathrm{~mm}$ and $2 \mathrm{~mm}$ for the $\mathrm{Fe}_{74} \mathrm{Al}_{4} \mathrm{Sn}_{2} \mathrm{P}_{12} \mathrm{Si}_{4} \mathrm{~B}_{4}$ alloy. As

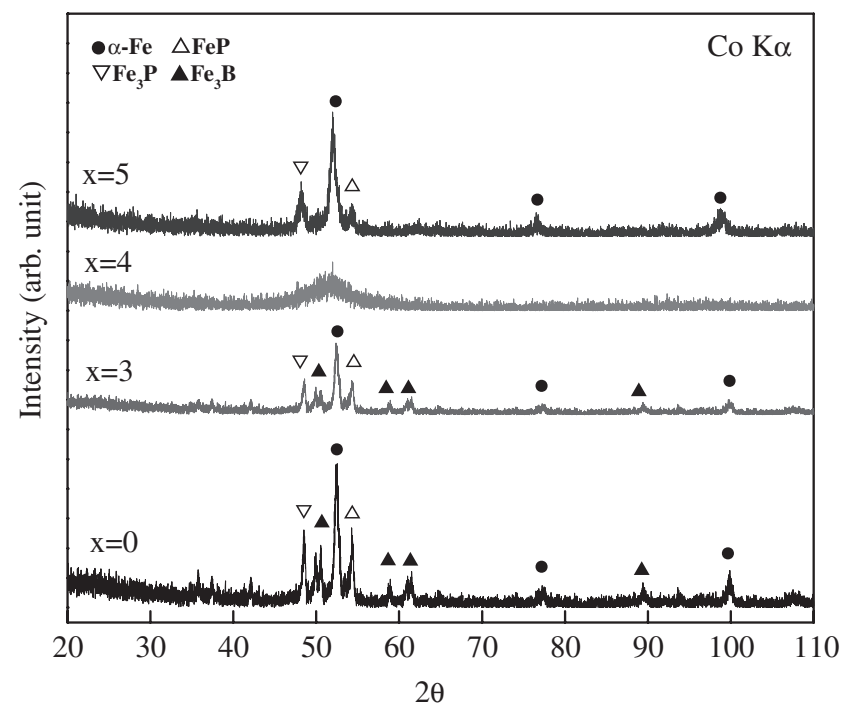

Fig. 4 X-ray diffraction patterns of copper-mold-cast rods of $\mathrm{Fe}_{78-x} \mathrm{Al}_{x} \mathrm{Sn}_{2} \mathrm{P}_{12} \mathrm{Si}_{4} \mathrm{~B}_{4}(x=0,3,4,5$ at $\%)$ alloys with a diameter $1 \mathrm{~mm}$.

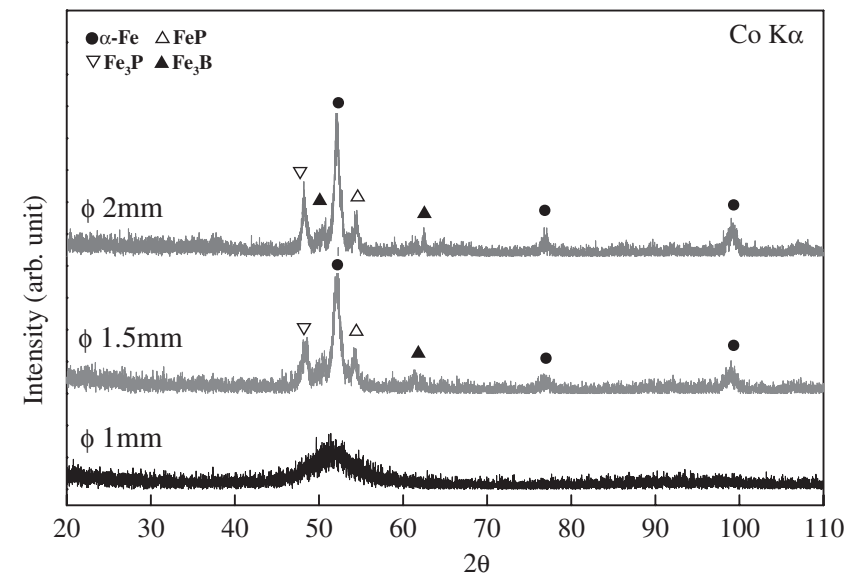

Fig. 5 X-ray diffraction patterns of copper-mold-cast rods with diameters $1 \mathrm{~mm}, 1.5 \mathrm{~mm}$, and $2 \mathrm{~mm}$, respectively, prepared from the $\mathrm{Fe}_{74}$ $\mathrm{Al}_{4} \mathrm{Sn}_{2} \mathrm{P}_{12} \mathrm{Si}_{4} \mathrm{~B}_{4}$ alloy.

shown in Fig. 5, the alloy crystallizes as the diameter increases to $1.5 \mathrm{~mm}$. This result reveals that a suitable addition of $\mathrm{Al}$ element does in fact improve the thermal stability and glass forming ability of Fe-Sn-P-Si-B alloy that is not able to cast into $1 \mathrm{~mm}$ rods. Comparing the thermal stability of Fe-Al-Sn-P-Si-B with Fe-Al-Ga-P-B-Si alloy; the $\Delta T_{\mathrm{x}}$ and the glass forming ability of $\mathrm{Fe}_{74} \mathrm{Al}_{4} \mathrm{Sn}_{2} \mathrm{P}_{12} \mathrm{Si}_{4} \mathrm{~B}_{4}$ alloy are slightly higher and better than those of $\mathrm{Fe}_{74} \mathrm{Al}_{4} \mathrm{Ga}_{2} \mathrm{P}_{12} \mathrm{Si}_{4} \mathrm{~B}_{4}$ alloy. Moreover, the $\mathrm{Sn}$ containing alloys are much more cost effective than the Ga containing ones.

The brittleness found in the $100 \sim 150 \mu \mathrm{m}$ thick FeSnPSiB amorphous ribbons (bent to a radius of curvature $>3 \mathrm{~mm}$ ) is much improved in these $\mathrm{Al}$ modified ones (bent to a radius of curvature $1 \mathrm{~mm}$ ). Thus winding into cores and other handlings are more readily feasible.

\subsection{Magnetic properties}

The magnetic properties of $\mathrm{Fe}_{78-x} \mathrm{Al}_{x} \mathrm{Sn}_{2} \mathrm{P}_{12} \mathrm{Si}_{4} \mathrm{~B}_{4}(x=0$, $3,4,5$ at \%) amorphous ribbons were shown in Fig. 6. The Curie temperature $\left(T_{\mathrm{c}}\right)$ decreases from $597.1 \mathrm{~K}$ at $\mathrm{Al}=0$ at $\%$ to $578.3 \mathrm{~K}$ as $\mathrm{Al}$ content increases to 5 at $\%$, since the addition of $\mathrm{Al}$ atom has no more contribution to magnetic interaction among iron atoms but increases the average distance between iron atoms leading to a decreased exchange interaction, hence $T_{\mathrm{c}}$.

An annealing at $723 \mathrm{~K}$ (below crystallization temperature) for $600 \mathrm{~s}$ leads to a substantial improvement in soft magnetic properties, as shown in Fig. 7. With increasing Al content, the maximum permeability $\left(\mu_{\mathrm{m}}\right)$ is greatly improved and continually increases from $137000(x=3)$ to $208000(x=5), H_{\mathrm{c}}$ goes down from 3.8 to $2.2 \mathrm{~A} / \mathrm{m}$ and $I_{\mathrm{s}}$ only slightly reduces from 1.22 to $1.18 \mathrm{~T}$. The reason for permeability improvement is proposed to arise from the 'Sendust behavior' (Sendust is an Fe-Al-Si alloy which exhibits extremely high permeability). The replacement of Fe by $\mathrm{Al}$ in the FeSnPSiB alloys may favor the formation of 'sendust-like' composition domains that facilitates the permeability.

The magnetic properties of $\mathrm{Fe}_{78-x} \mathrm{Al}_{x} \mathrm{Sn}_{2} \mathrm{P}_{12} \mathrm{Si}_{4} \mathrm{~B}_{4}(x=0$, $3,4,5$ at \%) amorphous alloys are much better than the values reported of Fe-Al-Ga-P-B-Si amorphous alloys with optimal 


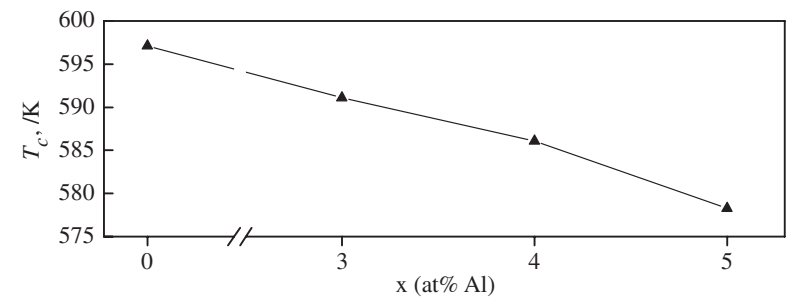

Fig. 6 Change in Curie temperature with $\mathrm{Al}$ content for melt-spun amorphous $\mathrm{Fe}_{78-x} \mathrm{Al}_{x} \mathrm{Sn}_{2} \mathrm{P}_{12} \mathrm{Si}_{4} \mathrm{~B}_{4}(x=0,3,4,5$ at\%) ribbons.

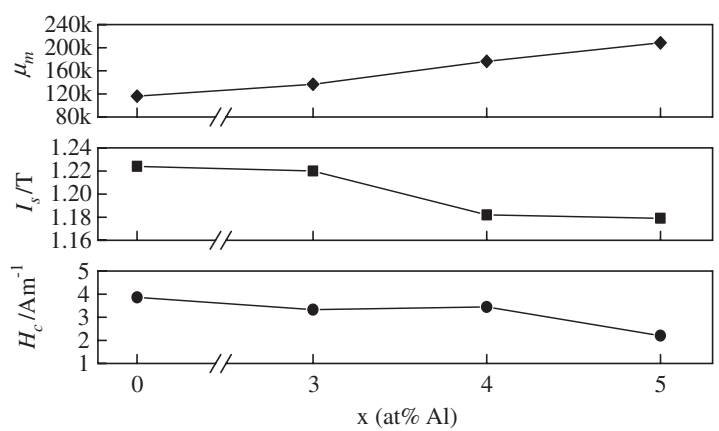

Fig. 7 The DC maximum permeability $\left(\mu_{\mathrm{m}}\right)$, saturation magnetization $\left(I_{\mathrm{s}}\right)$, and coercive force $\left(H_{\mathrm{c}}\right)$ as a function of $\mathrm{x}$ for melt-spun $\mathrm{Fe}_{78-x} \mathrm{Al}_{x} \mathrm{Sn}_{2} \mathrm{P}_{12} \mathrm{Si}_{4} \mathrm{~B}_{4}(x=0,3,4,5$ at $\%)$ amorphous ribbons annealed at $723 \mathrm{~K}$ for $600 \mathrm{~s}$.

$I_{\mathrm{s}} 1.14 \mathrm{~T}$ and $H_{\mathrm{c}} 6.4 \mathrm{~A} / \mathrm{m} .{ }^{30)}$ As a comparison, the maximum permeability $\left(\mu_{\mathrm{m}}\right)$ of the $\mathrm{Fe}_{78-x} \mathrm{Al}_{x} \mathrm{Sn}_{2} \mathrm{P}_{12} \mathrm{Si}_{4} \mathrm{~B}_{4} \quad(x=$ $3 \sim 5$ at\%) amorphous alloys spans from 137000 to 208000 , which are much better than the value 110000 reported for the $\mathrm{Fe}_{70} \mathrm{Al}_{5} \mathrm{Ga}_{2} \mathrm{P}_{9.65} \mathrm{C}_{5.75} \mathrm{~B}_{4.6} \mathrm{Si}_{3}$ alloy in a bulk amorphous ring shape form. ${ }^{32)}$

The electrical resistivity $(\rho)$, which is the higher the better for reduction of eddy current under an alternative magnetic field in transformer applications, increases linearly from 175 to $188 \mu \Omega$-cm with increasing $\mathrm{Al}$ content in $\mathrm{Fe}_{76-x} \mathrm{Al}_{x^{-}}$ $\mathrm{Sn}_{2} \mathrm{P}_{12} \mathrm{Si}_{4} \mathrm{~B}_{4}$ alloys. The reason for electrical resistivity increment is supposed to arise from the improved degree of random packed structure leading to a reduced mean free path of electron hence a larger scattering effect. The electrical resistivity of these alloys is much higher than that of $\mathrm{Fe}_{78} \mathrm{Si}_{9} \mathrm{~B}_{13}$ amorphous alloy, which is $140 \mu \Omega$-cm.

Core loss is an important factor for the applications in transformers. Figure 8 shows the core loss at a frequency $50 \mathrm{~Hz}$ and a maximum flux density $\left(B_{\mathrm{m}}\right) \quad 1.1 \mathrm{~T}$ for $\mathrm{Fe}_{76-x} \mathrm{Al}_{x} \mathrm{Sn}_{2} \mathrm{P}_{12} \mathrm{Si}_{4} \mathrm{~B}_{4}(x=3 \sim 5$ at\% $)$ glassy ribbons. The core loss does not exhibit a regular relation with $\mathrm{Al}$ content and shows an average value merely $0.14 \mathrm{~W} / \mathrm{kg}$ for the $\mathrm{Fe}_{74} \mathrm{Al}_{4} \mathrm{Sn}_{2} \mathrm{P}_{12} \mathrm{Si}_{4} \mathrm{~B}_{4}$ alloy.

\section{Conclusions}

The thermal stability is improved by partial replacement of Fe with $\mathrm{Al}$ in the $\mathrm{Fe}_{78} \mathrm{Sn}_{2} \mathrm{P}_{12} \mathrm{Si}_{4} \mathrm{~B}_{4}$ alloy. Super-cooled liquid region is extended from $40.6 \mathrm{~K}$ (without $\mathrm{Al}$ ) to a maximum $50.2 \mathrm{~K}$ for the $\mathrm{Fe}_{74} \mathrm{Al}_{4} \mathrm{Sn}_{2} \mathrm{P}_{12} \mathrm{~B}_{4} \mathrm{Si}_{4}$ amorphous alloy. The optimal magnetic properties for $\mathrm{Fe}_{78-x} \mathrm{Al}_{x} \mathrm{Sn}_{2} \mathrm{P}_{12} \mathrm{Si}_{4} \mathrm{~B}_{4}$ $(x=3 \sim 5$ at $\%)$ amorphous ribbons annealed at $723 \mathrm{~K}$ for

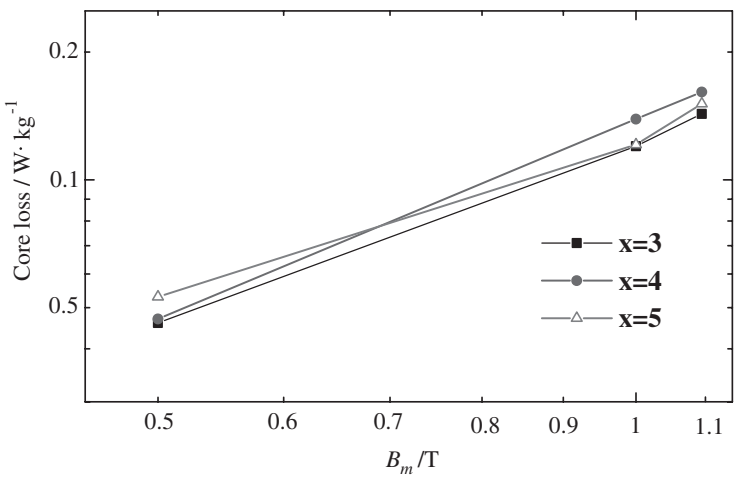

Fig. 8 Variation in core loss of melt-spun $\mathrm{Fe}_{78-x} \mathrm{Al}_{x} \mathrm{Sn}_{2} \mathrm{P}_{12} \mathrm{Si}_{4} \mathrm{~B}_{4}(x=3,4$, 5 at $\%$ ) amorphous ribbons with thickness $30 \mu \mathrm{m}$, annealed at $723 \mathrm{~K}$ for $600 \mathrm{~s}$.

$600 \mathrm{~s}$ are: saturation magnetization $1.22 \mathrm{~T}$; coercive force $2.20 \mathrm{~A} / \mathrm{m}$, maximum permeability $\left(\mu_{\mathrm{m}}\right) 208000$, core loss $0.14 \mathrm{~W} / \mathrm{kg}(50 \mathrm{~Hz}, 1.1 \mathrm{~T}$ external magnetic field); Curie temperature from $591.1 \mathrm{~K}$ to $578.3 \mathrm{~K}$, the electrical resistivity from 175.4 to $188 \mu \Omega-\mathrm{cm}$. Bulk amorphous rods with $1 \mathrm{~mm}$ diameter have also been successfully demonstrated for the $\mathrm{Fe}_{74} \mathrm{Al}_{4} \mathrm{Sn}_{2} \mathrm{P}_{12} \mathrm{Si}_{4} \mathrm{~B}_{4}$ alloy. With the combination of good glass forming ability and soft magnetic properties, it shows that $\mathrm{Fe}-\mathrm{Al}-\mathrm{Sn}-\mathrm{P}-\mathrm{Si}-\mathrm{B}$ amorphous alloys are very promising for industrial applications.

\section{REFERENCES}

1) P. Duwez and C. H. Lin: J. Appl. Phys. 38 (1967) 4096-4097.

2) R. C. Sherwood, E. M. Gyorgy, H. S. Chen, S. D. Ferris, G. Norman and H. J. Leamy: AIP Conf. Proc. 24 (1974) 745-746.

3) T. Egami, P. J. Flanders and C. D. Graham: AIP Conf. Proc. 24 (1974) 697-701.

4) H. Fujimori, T. Masumoto, Y. Chi and M. Kikuchi: Jpn. J. Appl. Phys. 13 (1974) 1889-1890.

5) A. Inoue, T. Masumoto, S. Arakawa and T. Iwadachi: Rapidly Quenched Metals III. Vol. I (Metal Society, 1978) 265-272.

6) M. Nose and T. Masumoto: Sci. Rep. Res. Inst. Tohoku Univ. A-28 (1980) 232-241.

7) A. Inoue, K. Kobayashi and T. Masumoto: Proc. Conf. on Metallic Glasses. Sci. Tech., Budapest (1980) 217-222.

8) A. Inoue, K. Kobayashi, J. Kanehira and T. Masumoto: Sci. Rep. Res. Inst. Tohoku Univ. A-29 (1981) 331-342.

9) A. Inoue, A. Kato, T. Zhang, S. G. Kim and T. Masumoto: Mater. Trans., JIM 32 (1991) 609-616.

10) A. Inoue and T. Masumoto: Mater. Sci. Eng. A173 (1993) 1-8.

11) A. Inoue, K. Kita, T. Zhang and T. Masumoto: Mater. Trans., JIM 30 (1989) 722-725.

12) A. Inoue, T. Zhang and T. Masumoto: Mater. Trans., JIM 31 (1990) $425-428$.

13) A. Inoue, T. Zhang, N. Nishiyama, K. Ohba and T. Masumoto: Mater. Trans., JIM 34 (1993) 1234-1237.

14) A. Inoue, T. Saito, H. Yamamoto and T. Masumoto: J. Mater. Sci. Lett. 12 (1993) 946-948.

15) A. Peker and W. L. Johnson: Appl. Phys. Lett. 63 (1993) 2342-2344.

16) A. Inoue and J. S. Gook: Mater. Trans., JIM 36 (1995) 1282-1285.

17) A. Inoue and J. S. Gook: Mater. Trans., JIM 37 (1996) 32-38.

18) A. Inoue, Y. Shinohara and J. S. Gook: Mater. Trans., JIM 36 (1985) 1427-1433.

19) A. Inoue, A. Murakami, T. Zhang and A. Takeuchi: Mater. Trans., JIM 38 (1997) 189-196.

20) A. Inoue, T. Zhang and T. Itoi: Mater. Trans., JIM 38 (1997) 359-362.

21) A. Inoue, M. Koshiba, T. Zhang and A. Makino: Meter. Trans., JIM 38 (1997) 577-582. 
22) M. Koshiba, A. Inoue and A. Makino: J. Appl. Phys. 85 (1999) 51365138.

23) A. Inoue, T. Zhang and A. Takeuchi: Appl. Phys. Lett. 71 (1997) 464 466.

24) W. Zhang and A. Inoue: Mater. Trans., JIM 40 (1999) 78-81.

25) A. Inoue, T. Zhang, W. Zhang and A. Takeuchi: Mater. Trans., JIM 37 (1996) 99-108

26) A. Inoue, T. Zhang and A. Takeuchi: Mater. Trans., JIM 37 (1997) 1731-1740.

27) A. Inoue, T. Zhang and A. Takeuchi: IEEE Trans. Magn. 33 (1997) 3814-3816.
$28)$ T. S. Chin, C. K. Chao, C. Y. Lin, J. C. Shih, S. X. Zhou, Z. C. Lu, L. Wang and F. F. Chen: IEEE Trans. Mag. 39 (2003) 3016-3018.

29) Binary Alloy Phase Diagrams second edition, ed. By T. B. Massalski, H. Okamato, P. R. Subramanian and L. Kacprzak, (ASM International, Materials Park, Ohio, 1990).

30) A. Inoue and R. E. Park: Mater. Trans., JIM 37 (1996) 1715-1721.

31) A. Makino, A. Inoue and T. Mizushima: Mater. Trans., JIM 41 (2000) 1471-1477.

32) K. Ikarashi, T. Mizushima, A. Makino and A. Inoue: Mater. Sci. Eng. A304 (2001) 763-766. 